Dr. Martinus Sardi, MA.

Fakultas Hukum, Universitas Muhammadiyah Yogyakarta, Jl. Lingkar Selatan, Tamantirto,

Kasihan, Bantul, Yogyakarta. E-Mail: msardi123agmail.com

\title{
Membangun Budaya Hak-Hak Asasi Manusia
}

\author{
Naskah Masuk: 3 Januari 2016 // Naskah Diterima: 8 Maret 2016
}

DOI: 10.18196/jmh.2015.0073.121-127

\begin{abstract}
:
The violations of Human Rights remain spread in all over the world until now. There are violations of Human Rights in all the countries in this universe. It is not possible to find a country, which free from this violation. It is very terrible, such as the professional killing and systematic murder. It will cause to grow the culture of dead. This culture does not respect on the human life. The professional killing and systematic murder are real social fact, which are not distinct and justly resolved. This criminal actions will grow more terrible, if the official organs of the government provoke and take apart in this matter, do not want to obstacle and stop them, although they are capable to do it. The culture of Human Rights can be built, if the culture of life has been respected, the people, especially the organ of the government takes care and respect to Human Rights and promote them as well as possible. So the human life will grows to the directions of the welfare for the people and more civilized. If the people develop the culture of Human Rights, the human civilizations will grow for respect them. We have task to develop the culture of Human Rights.

Key Words: Human Rights, Violations of Human Rights, Culture of Human Rights, Culture of Life and Death.
\end{abstract}

\section{ABSTRAK}

Sampai saat ini pelanggaran HAM masih terjadi hampir di seluruh dunia. Di semua Negara terjadi pelanggaran HAM, tiada satu Negara pun di bumi ini yang bebas dari pelanggaran HAM. Pelanggaran HAM yang begitu mengerikan adalah pembunuhan atau penghilangan nyawa secara sistematis dan disengaja. Pemunuhan yang demikian itu akan melahirkan apa yang biasanya diistilahkan dengan budaya kematian. Budaya kematian itu menunjukkan bahwa kehidupan ini tidaklah dihargai. Tiada respek akan kehidupan manusia. Pembunuhan terjadi di mana-mana, tanpa penyelesaian yang pasti dan jelas. Tindak kejahatan ini akan semakin mengerikan, bila penguasa atau organ Negaralah yang memerintahkan atau ikut terlibat di dalamnya, atau tidak mau menghentikannya, sekalipun mereka itu mampu. Budaya HAM akan dapat dibangun bila budaya kehidupan mulai diperhatikan, dipelihara dan dikembangkan dengan baik. Dengan demikian kehidupan manusia ini akan semakin sejahtera dan beradab. Semakin budaya HAM ini berkembang, peradaban manusia akan semakin berkembang juga, sebaliknya bila pelanggaran HAM tidak ditangani secara serius dan professional, kehidupan manusia akan semakin biadab. Kata-kata Kunci: Hak-Hak Asasi Manusia, Pelanggaran HAM, Budaya HAM, Budaya Kehidupan dan Kematian.

\section{PENDAhULUAN}

Kalau kita mencermati berbagai laporan tahunan keadaan Hak Asasi Manusia (HAM) di 
negara kita, ternyata Negara kita masih belum bebas dari adanya pelanggaran HAM.

Pelanggaran HAM dalam berbagai bentuk, secara khusus pembunuhan atau penghilangan nyawa secara sengaja, masih terjadi di Negara kita dan banyak yang belum diselesaikan secara tuntas. Hampir setiap hari terjadi pelanggaran HAM, dan tidak jarang penghilangan nyawa secara sengaja. Seolah tiada hari tanpa pelanggaran HAM (Bdk. Ana Filipa Vrdoljak, 2012, 163-188, Geoffrey Robertson QC, 2010, Martinus Sardi, 2014, 31-40, Raoy Gutman dan David Rieff (eds), 1999, US Department of the States, 2015, 6-14). Penghargaan dan respek akan hidup manusia masih jauh dari sempurna. Dalam situasi yang demikian ini sangatlah penting untuk menggagas adanya grand design untuk membangun Budaya HAM (Bdk. Jeremy Sarkin, 1998, 628-665, Martinus Sardi, 2015, 451-457).

Budaya HAM akan terbangun bila budaya kehidupan itu dipelihara dengan baik, dan pelanggaran HAM semakin mengecil. Kematian para pejuang HAM dan kemanusiaan, misalnya Munir yang tragis merupakan tanda bahwa budaya kehidupan belumlah terbangun. Budaya kematian masih menyelimuti berbagai komponen kekuasaan negara kita. Kematian Munir dan banyak pejuang HAM dan kemanusiaan di Negeri ini telah meninggalkan luka yang menganga dan wajah pelaksanaan HAM kita masih perlu perjuangan selanjutnya. Budaya kematian atau dengan penghilangan nyawa yang secara professional, sistematis dan terencana tanda bahwa di negara kita ini belum tertanam dan mengakar adanya budaya kehidupan. Membunuh sesama manusia, terutama mereka yang dianggap kritis terhadap penguasa, vokal dan menyuarakan kebenaran dan keadilan, bagaikan menyembelih ayam potong saja. (Bdk. Ana Filipa Vrdoljak, 2012, 163-188, Geoffrey Robertson QC, 2010, Martinus Sardi, 2014, 31-40, Raoy Gutman dan
David Rieff (eds), 1999, US Department of the States, 2015, 6-51).

Sungguh suatu fakta yang sulit dipungkiri. Kematian Munir yang tidak kunjung terungkap secara transparan, siapa pelaku sebenarnya merupakan kekalahan organ negara kita dalam menegakkan HAM dan membangun budaya kehidupan. Organ negara yang seharusnya berkompeten mengungkap setuntas-tuntasnya tragedi kematian Munir, menjadi macet dan tidak mampu. Orang boleh bertanya, kalau kasus yang begitu resent atau baru saja tidak dapat diungkap secara tuntas, bagaimana mungkin organ negara kita dapat menangani berbagai kasus yang sudah lama di masa lalu dan lebih kompleks? Sungguh suatu yang pantas disayangkan. Ataukah organ negara kita tidak mau mengungkapnya secara tuntas?(Bdk. Daniel Jonah Goldhagen, 2007, Franciszek Piper dan Teresa Swiebocka, 2005, Geoffrey Robertson QC, 2010).

Yang jelas, dengan adanya berbagai tragedi kematian, khususnya karena penghilangan nyawa secara sengaja di negara ini, dapatlah dinyatakan bahwa budaya kematian masih meraja-lela di Indonesia. Budaya kematian belum hilang di bumi kita ini. Mungkinkah budaya kematian dengan ciri khas penghilangan nyawa seperti itu akan musnah dari bumi Indonesia ini? Kalau semua organ negara kita dan setiap warga masyarakat berkehendak baik mencintai kehidupan, kita yakin bahwa budaya kematian akan berakhir dan budaya kehidupan akan berkembang. Budaya kehidupan seharusnya mengalahkan budaya kematian. Di situlah awal tumbuhnya nilai-nilai kemanusiaan, HAM akan semakin berkembang dengan baiknya, keamanan manusia akan terjamin, dan selanjutnya budaya HAM dapat dibangun di Negara kita (Bdk. Ana Filipa Vrdoljak, 2012, 163-188, Candra Gautama dan B.N Marbun (ed), 2000, Barry Buzan, 1991, Martinus Sardi, 2003, 207 - 219). 
Berdasarkan uraian tersebut di atas dapatlah dirumuskan permasalahan yang perlu digali: Bagaimanakah Budaya Hak Asasi Manusia itu harus dibangun di Negara kita?

\section{PERLINDUNGAN DAN PEMAJUAN HAK- HAK ASASI MANUSIA}

Deklarasi Vienna tahun 1993, hasil dari Konferensi dunia yang diadakan Perserikatan Bangsa-Bangsa, mencanangkan suatu program dan aksi serta agenda untuk bertindak berkenaan dengan Perlindungan dan Pemajuan Hak-Hak Asasi Manusia. Sebab pelanggaran HAM sangatlah memprihatinkan. Dalam Deklarasi Vienna ini antara lain dinyatakan, "Konferensi Dunia Hak Asasi Manusia menyatakan keprihatinan yang sangat terhadap pelanggaran Hak Asasi Manusia yang terus terjadi di semua tempat di dunia, yang dilakukan tanpa menghargai standar yang terkandung dalam instrumen Hak Asasi Manusia internasional dan hukum kemanusiaan internasional, serta terhadap kurangnya bantuan yang memadai dan efektif untuk para korban. Konferensi Dunia Hak Asasi Manusia sangat prihatin terhadap pelanggaran Hak Asasi Manusia yang terjadi pada saat konflik bersenjata berlangsung, yang berpengaruh terhadap masyarakat sipil terutama perempuan, anak, mereka yang Ianjut usia dan para penyandang cacat...”. (Deklarasi Vienna, no. 20) Banyak pihak yang tidak mematuhi hukum internasional dan bertindak tidak manusiawi. Akibatnya pelanggaran HAM terjadi terusmenerus tiada hentinya. Oleh karena itu pantaslah kalau, "Konferensi Dunia Hak Asasi Manusia juga mengutuk dan menyatakan kekhawatirannya atas pelanggaran berat yang sistematis dan keadaan yang menyebabkan hambatan serius bagi penerapan semua Hak Asasi Manusia secara seutuhnya yang terus berlangsung di berbagai tempat di dunia. Pelanggaran dari hambatan tersebut antara lain penyiksaan, perlakuan atau hukuman yang kejam, tidak manusiawi dan merendahkan martabat, eksekusi kilat dan sewenang-wenang, pelenyapan orang-orang, penahanan yang sewenang-wenang, semua bentuk rasisme, diskrinunasi rasial dan apartheid, pendudukan oleh bangsa lain dan dominasi asing, xenofobia, kemiskinan, kelaparan. dan pengingkaran lainnya terhadap hak ekonomi, sosial dan budaya, tidak adanya toleransi beragama terorisme, diskriminasi terhadap perempuan dan juga tidak adanya norma hukum. (Deklarasi Vienna, no. 30). Pelanggaran HAM yang paling mengerikan adalah pembunuhan atau penghilangan nyawa yang sengaja, sistematis dan professional. Sungguh sangat mengerikan (Bdk. Ana Filipa Vrdoljak, 2012, 163-188, Barry Buzan, 1991, Candra Gautama dan B.N Marbun (ed), 2000, Martinus Sardi, 2003, 207 219, Geoffrey Robertson QC, 2010).

Hak-hak Asasi Manusia dalam segala situasinya bagaimana pun juga haruslah mendapat perlindungannya dari pihak pemerintah dan harus diperjuangkan oleh semua pihak. Perlindungan dan Perjuangan untuk mengimplementasikan HAM dalam kehidupan bermasyarakat dan bernegara akan mengarahkan adanya pemenuhan HAM bagi warganya. Pelanggaran HAM akan semakin dikurangi, dan sedapat mungkin diatasi oleh semua pihak, terutama oleh organ Negara yang resmi dan masyarakat sipil. Perjuangan HAM merupakan perjuangan kemanusiaan dan dilaksanakan demi tercapainya pemenuhan HAM bagi semua manusia yang hidup di dunia ini. Dengan demikian nilai manusia manusia dan martabatnya akan semakin dijunjung tinggi dan dihargai. Pelanggaran terhadap HAM dan pelecehannya akan semakin dikikis habis.

Dengan adanya pelanggaran HAM itu, harga diri manusia benar-benar dihina, dilecehkan dan begitu direndahkan, apalagi pelanggaran itu berupa penghilangan nyawa secara sengaja, 
sistematis dan professional. Tindakan itu dapat dikatakan sebagai tindakan yang biadab, bagaikan peradaban manusia sudah tidak ada lagi. Dalam rangka itu, Konferensi dunia yang diselenggarakan di Vienna, Austria tahun 1993 itu mengajak semua pihak terutama pemerintah Negara untuk ikutserta masyarakat dunia mengkikis habis pelanggaran HAM, dengan melindungi semua warganya dan mempromosikan HAM dalam situasi apapun juga. HAM tidaklah boleh dihina dan dilecehkan oleh siapapun juga, terutama oleh mereka yang memegang kekuasaan Negara dan pemerintah. Kalau HAM semakin mendapat perlindungannya, dan penuhan seutuhnya HAM itu akan terlaksana, maka budaya HAM kiranya akan dapat dibangun. Budaya HAM sungguh sangat penting dikembangkan di jaman sekarang ini demi generasi yang mendatang agar semakin respek akan hidup manusia yang seutuhnya (Bdk. Georg Lehmann, 1998, Jeremy Sarkin, 1998, 628-665, Martinus Sardi, 2012, 71 - 92).

\section{DARI INSTRUMEN HAM KE BUDAYA HAM}

Dalam rangka melindungi rakyat serta hakhaknya, Pemerintah bersama dengan Dewan Perwakilan Rakyat haruslah meratifikasi berbagai instrument hukum internasional dengan membuat undang-undang yang bertujuan mau menjamin hak-hak asasi manusia itu. Kebanyakan ratifikasi dari pihak Indonesia merupakan ratifikasi telanjang atau ratifikasi yang kurang mau melindungi kesejahteraan rakyat dan mau menghindar dari tuntutan hukum internasional. Kita dapat mengambil contoh mengenai bagaimanakah hak-hak asasi anak harus dilindungi. Terhadap perhatian akan hak-hak asasi anak ini benar-benar kelihatan bahwa negara Indonesia tidak mau adanya tuntutan standard internasional dalam ratifikasi hukum internasional, khususnya mengenai perlindungan hak-hak asasi anak. Ratifikasi yang seharusnya dilaksanakan dalam bentuk UndangUndang yang pasti jaminannya, oleh Pemerintah Indonesia ratifikasi itu dilaksanakan dalam bentuk Keptusan Presiden Soeharto. Memang keputusan Presiden itu juga dapat dipakai sebagai tata aturan untuk meratifikasi hukum internasional. Tampaknya suatu hukum internasional ditanggapi dengan keputusan Presiden, yang sama sekali tidak memberikan jaminan atau perlindungan pada hak-hak asasi anak, sebaliknya malah mau melepaskan diri dari tanggungjawab pada tuntutan internasional (Bdk. Ana Filipa Vrdoljak, 2015, Martinus Sardi, 2012, 71 - 92, Satjipto Rahardjo, 2005, 217 - 226).

Sehubungan dengan jaminan perlindungan terhadap kesejahteraan rakyat, Undang-Undang Nomor 39 tahun 1999 tentang Hak-Hak Asasi Manusia juga kurang memberikan garansinya di negara kita. Karena kalau hak-hak asasi manusia itu dilanggar, apakah sanksi pidana pelanggaran itu? Dan apakah para korban pelanggaran hak asasi manusia itu dilindungi oleh hukum hak asasi manusia yang pasti? Serta bagaimanakah para korban pelanggaran hak asasi manusia itu dilindungi dan dapat mencari perlindungan? Instrumen hukum atau sarana yuridis yang pasti mengenai hal ini tidaklah tegas secara transparan bagi rakyat Indonesia. Hal ini berbeda jauh sekali dengan warga Uni-Eropa yang kalau merasa diri hak-hak asasinya dilanggar, mereka bahkan secara pribadi dapat mengajukan ke pengadilan Hak Asasi Manusia di Strasbourg, Prancis. Memang dalam UndangUndang mengenai Hak-Hak Asasi Manusia secara jelas dideretkan hak-hak asasi manusia Indonesia, akan tetapi bagaimanakah dan dengan cara apakah hak-hak asasi itu benarbenar mendapat perlindungan yang pasti? Juga dalam Undang-Undang Nomor 26 tahun 2000 tentang Pengadilan Hak Asasi Manusia di negara kita tidaklah berisikan suatu jaminan apapun terhadap kesejahteraan rakyat. 


\section{4 \\ JURNAL MEDIA HUKUM}

Pengadilan Hak-Hak Asasi Manusia hanya mengatur bagi pelanggaran hak-hak asasi yang berat saja (kejahatan genosaid dan kejahatan melawan kemanusiaan), sedangkan pelanggaran hak-hak asasi biasa tidaklah mendapat yurisdiksinya dalam Pengadilan HAM. Dengan demikian perlindungan terhadap hak-hak asasi manusia tetaplah menjadi persoalan aktual yang harus segera diselesaikan di Indonesia, paling tidak dari segi yuridis-praktis. Perlindungan hakhak asasi biasa bagaimana pun juga haruslah ada, demi kesejahteraan rakyat. Persoalannya ialah bagaimana dan ke manakah orang-orang yang menjadi korban pelanggaran hak-hak asasi biasa - artinya tidak tergolong pelanggaran yang berat - dapat mengadu dan mencari keadilan? Jaminan dan garansi untuk hal itu masih belum ada, dan belum tercakup dalam UndangUndang tentang pengadilan Hak-hak Asasi Manusia. Pelanggaran HAM yang biasa saja digolongkan dalam pelanggaran dalam yurisdiksi pengadilan pidana biasa, dan bukan dalam yurisdiksi pengadilan HAM (Bdk. Muladi (ed.), 2005, 99-110, Sunarto, 137-148).

Dari berbagai instrumen HAM baik nasional maupun internasional yang disahkan oleh Perserikatan Bangsa-Bangsa, mau menunjukkan bahwa rakyat itu seharusnya memperoleh dan menikmati HAMnya dan sekaligus juga mempunyai kesempatan untuk mengembangkannya semaksimal mungkin (Bdk. Ana Filipa Vrdoljak, 2012, 163-188, Candra Gautama dan B.N Marbun (ed), 2000, Geoffrey Robertson QC, 2010, Georg Lehmann dan Stefan Gosepath, Suhrkamp (ed.), 1998)

Pengembangan HAM dan perlindungan terhadapnya sebagaimana dicanangkan oleh Deklarasi Viena tahun 1993 dan Deklarasi Millenium tahun 2000 haruslah mampu untuk menciptakan budaya HAM. Budaya HAM dapat lahir dimulai dengan respek terhadap kehidupan dan hak-hak yang terkait dengannya. Hak-Hak dasar yang tidak boleh dilecehkan antara lain hak hidup, mengembangkan diri, pengakuan di hadapan hukum, non diskriminasi, privacy, hak milik, kebebasan beragama, keamanan, kedamaian, keluarga, dls. haruslah dipromosikan sedemikian rupa, sehingga setiap orang tahu, sadar dan siap sedia untuk mengembangkannya serta respek terhadapnya. Hal ini akan menjadi lebih lengkap dengan dipromosikannya keamanan manusia. (Bdk. Barry Buzan, 1991, Candra Gautama dan B.N Marbun (ed), 2000, Geoffrey Robertson QC, 2010, Jeremy Sarkin, 1998, 628665, Martinus Sardi, 2015, 451-457).

Bila kita memperhatikan studi tentang keamanan, mula pertama yang menjadi fokus adalah keamanan negara atau keamanan dari sudut militer, lalu dengan berkembang arah globalisasi, keamanan dilihat paling tidak dari lima sudut pandang military security, political security, economic security, societal security, dan environmental security. Keamanan negara itu penting, tetapi arah keamanan manusia itu menjadi fokus dari HAM. HAM mau menekankan betapa pentingnya manusia itu memperoleh hak-haknya, khususnya rasa aman, damai dan tenteram, tanpa adanya ancaman apapun dari siapapun juga. Berbagai instrumen HAM memang menekankan betapa pentingnya nilai hidup manusia itu dan harus mendapat perlindungannya yang pasti. HAM justru akan berkembang dengan baiknya, bila keamanan manusia itu diberi tempatnya yang layak. Dengan demikian budaya HAM itu akan berkembang. Budaya HAM akan berkembang dengan kerjasama semua pihak untuk mempromosikan dalam segala aspeknya, dan melanggar HAM haruslah dinilai sebagai tindakan yang tidak beradab (Bdk. Ana Filipa Vrdoljak, 2012, 163-188, Barry Buzan, 1991, Candra Gautama dan B.N Marbun (ed), 2000, Geoffrey Robertson QC, 2010, Martinus Sardi, 2012, 71 - 92, Satjipto Rahardjo, 2005, 217 226). 


\section{BUDAYA HAM DAN KEAMANAN MANUSIA DALAM NEGARA YANG DEMOKRATIS}

Budaya HAM haruslah diciptakan dan mulai tertanam di negara kita. Dan hal ini akan menjadi nyata dengan dimulainya respek akan hak hidup manusia. Itu berarti keamanan manusia terjamin. Hidup manusia tidaklah boleh diancam, ditekan atau pun dilecehkan. Pelanggaran HAM haruslah semakin dikikis habis, apalagi penghilangan nyawa secara sengaja, sistematis dan profesional. Hak-hak Asasi Manusia tidaklah boleh dilecehkan oleh siapapun juga. Hak-hak Asasi Manusia haruslah menjadi titik sentral pelaksanan demokratisasi. Demokrasi berarti pemerintahan dari rakyat, oleh rakyat dan untuk rakyat. Dengan demikian sovranitas kekuasaan itu di tangan rakyat. Rakyat berkuasa. Kekuasaan rakyat itu dapat dalam bentuk perwakilan dalam pemerintahan, parlemen ataupun dalam kontrol terhadap siapapun yang memegang kekuasaan itu sendiri (Kurt Tudyka, 1992, 4-13\}. Dalam era demokrasi, perjuangan hak-hak asasi manusia, perlindungan, pengembangan dan pemajuannya tidaklah boleh dihalangi, dan hak-hak asasi itu sendiri mendapat jaminannya dari hukum yang adil dan pasti.

Negara yang menganut demokrasi itu mau menjamin dan melindungi rakyatnya. Dalam kenyataannya demokrasi, yang berarti "kuasa itu dari rakyat, oleh rakyat dan untuk rakyat" tetaplah jauh dari kenyataan. Negara diselenggarakan dan dikuasai oleh suatu pemerintah yang pada umumnya belum mampu memperhatikan kepentingan dan kesejahteraan rakyat, termasuk di dalamnya keadilan. Dalam rangka itu, Deklarasi Vienna mau mengajak betapa pentingnya adanya suatu demokratisisasi yang disertai dengan pembangunan dan respek akan hak-hak asasi manusia serta kebebasan yang dasariah, yang semuanya itu saling tergantung dan saling mempengaruhi satu sama lain. Demokrasi haruslah merupakan suatu dasar dari adanya kebebasan bagi rakyat untuk menyatakan pendapatnya dalam bidang politik, ekonomi, sosial dan sistem budaya, dan rakyat yang sama itu diberi kesempatan untuk ikut ambil bagian secara aktif dalam menyelenggarakan kekuasaan. Kekuasaan ada di tangan rakyat dan dilaksanakan oleh rakyat dengan berbagai dimensinya. Rakyat tidaklah boleh dijadikan korban pelanggaran hak-hak asasi mereka, tetapi dijadikan sebagai subyek dan pusat segalanya dalam melaksanakan penyelenggaraan negara, dan penentuan kebijakan hidup sosial kemasyarakatannya. Rakyat pada jaman sekarang ini tidaklah boleh dikesampingkan dan dibiarkan begitu saja, tetapi harus diberi porsi yang integral dalam pembangunan, serta dijamin kesejahteraannya (Bdk. Daniel Jonah Goldhagen, 2007, Franciszek Piper dan Teresa Swiebocka, 2005, Geoffrey Robertson QC, 2010, Martinus Sardi, 861 - 867).

Yang menjadi persoalan sekarang ialah: bagaimanakah dan kondisi yang manakah yang dapat menciptakan situasi yang benar-benar demokratis, sehingga proteksi dan promosi hakhak asasi manusia itu dapat benar-benar terlaksana, rakyat mendapat perlindungan segala hak-haknya, kesejahteraan serta keadilan dapat dinikmati. Dalam rangka itu perlu adanya: kepastian hukum; perimbangan dalam trias politika antara kekuasaan legislatif, eksekutif dan yudikatif; dan penyelenggaraan negara dengan pemerintahan yang baik, jujur dan profesional (Bdk. Ana Filipa Vrdoljak, 2012, 163-188, Barry Buzan, 1991, Candra Gautama dan B.N Marbun (ed), 2000, Geoffrey Robertson QC, 2010, Martinus Sardi, 2001, 19. 48, Satjipto Rahardjo, 2005, 217 - 226).

Dalam situasi yang demikaian inilaah saatnya dibangun budaya HAM. Budaya HAM akan semakin berkembang dengan baik, bila organ Negara mau berjuang demi kesejahteraan rakyat 
dengan jaminan adanya perlindungan dan pengembangan HAM, dan terbuka akan kritik dari pihak rakyat. Bila HAM semakin diperhatikan, budaya HAM akan dapat tumbuh subur, dan akan semakin beradab, tetapi bila HAM tidak mendapat tempatnya yang layak serta masih banyak pelanggaran HAM, apalagi yang melanggar adalah organ Negara, maka tindakan yang biadab akan terjadi. Bagaimana pun jugaa dalam jaman ini, budaya HAM haruslah kita bangun dengan seluruh potensi yang ada dan kerjasama dengan semua pihak yang berkehendak baik (Bdk. Ana Filipa Vrdoljak, 2012, 163-188, Barry Buzan, 1991, Georg Lehmann, 1998, Jeremy Sarkin, 1998, 628-665, Martinus Sardi, 2016, 861 - 867).

\section{PENUTUP}

Pelanggaran HAM yang terjadi di seluruh dunia haruslah diperjuangkan untuk dkikis habis, sehingga hidup di dunia ini akan semakin beradab. Mungkinkah di Negara kita ini akan bebas dari pelanggaran HAM. Pelanggaran HAM yang begitu mengerikan adalah pembunuhan atau penghilangan nyawa secara sistematis, disengaja dan professional bagaimana pun juga tidak boleh terjadi lagi. Pemunuhan yang demikian itu, yang melahirkan budaya kematian haruslah diakhiri dengan seluruh kekuatan dan potensi yang ada dan bekerjasama dengan seluruh komponen masyarakat. Budaya kematian yang tidak respek akan kehidupan manusia tidaklah boleh dikembangkan lagi. Budaya yang respek akan kehidupan atau budaya kehidupan haruslah dikembangkan dan dipromosikan dalam seluruh aspek hidup masyarakat. Dari situlah Budaya HAM akan dapat dibangun. Budaya kehidupan diperhatikan, dipelihara dan dikembangkan di seluruh negara dalam segala segi dan aspeknya. Dengan demikian kehidupan manusia ini akan semakin beradab. Budaya HAM bagaimana pun juga harus dikembangkan dan peradaban manusia berkembang mencapai peradaban yang luhur. ${ }^{* * * *}$

\section{BIBLIOGRAFI}

Ana Filipa Vrdoljak, 2012: "Gross Violations of Human Rights and Restitution: Learning from Holocaust Claims", Selected Works of Ana Filipa Vrdoljak, University of Technology, Sydney, 163188.

Ana Filipa Vrdoljak (ed.), 2015: The Cultural Dimension of Human Rights, Oxford.

Candra Gautama dan B.N Marbun (ed), 2000: Hak Asasi Manusia: Penyelenggaraan Negara yang Baik dan Masyarakat Warga, Komisi Nasional Hak Asasi manusia, Jakarta.

Barry Buzan, 1991: People, State \& Fear: An Agenda for International Security Studies in the Post-Cold War Era, Harvester Wheatsheaf, New York. 19-20

Daniel Jonah Goldhagen, 2007: I Volonterosi Carnefici di Hitler: i tedeschi comuni e I'olocausto, Milano.

Franciszek Piper dan Teresa Swiebocka, 2005: Auschwitz: il campo della morte, Auschwitz-Birkenau.

Geoffrey Robertson QC, 2010: Crimes Against Humanity: The Struggle for Global Justice, Penguin Book.

Georg Lehmann dan Stefan Gosepath, Suhrkamp (ed.), 1998: Philosophie der Menshenrechte, Frankfurt am Mainz.

Georg Lehmann, 1998: "Menshenrechte: Zwitschen Moral und Recht", dalam: Georg Lehmann dan Stefan Gosepath, Suhrkamp (ed.), Philosophie der Menshenrechte, Frankfurt am Mainz.

Hermann Langbein, 2009: Die Menschen in Auschwitz, FrankfurtM, Berlin, Wien.

Jeremy Sarkin, 1998: "The Development of a Human Rights Culture in South Africa", dalam Human Rights Quarterly, (Vol. 20/ 1998) 628-665.

Keputusan Presiden No.36/1990, tanggal 25 Agustus 1990, Ratifikasi konvensi hak-hak anak. Konvensi ini mulai berlaku sebagi bagian integral dari hukum Indonesia sejak 5 Oktober 1990.

Kurt Tudyka, 1992, The Meaning of Democracy Today", dalam: Concilium (5/1992) 4-13.

Martinus Sardi, 2001: "Kepastian Hukum: jaminan Kesejahteraan Umum bagi Rakyat", dalam: Kontribusi IImu, Pengetahuan dan Teknologi dalam Penyelamatan Indonesia, Universitas Atma Jaya Yogyakarta p. 19-48.

Martinus Sardi, 2002: "Perlindungan dan Penyebarluasan Hak-Hak Asasi Manusia dalam Situasi Demokratis", dalam: Media Militer - Politik, Crisis Communications: Perspektif Indonesia dan Internasional (Friedrich Elbert Stiftung dan Galang Press, Yogyakarta, 171 - 183.

Martinus Sardi, 2003: "Conflict, Reconciliation toward Peace in the Indonesian Context: the role of Media and interreligious Dialogue", Proceeding International Seminar: Globalization, Religion, and Media in the Islamic World: Intercultural Dialogue, Yogyakarta, Octber 8th - 9 th, 2002 (Atma Jaya Yogyakarta University, Yogyakarta 2003), 207 - 219.

Martinus Sardi, 2010: "Multiculturalism: Base of the Challenges for the Promotion and Protection of Human Rights", dalam: Toward an Inclusive Democratic Indonesian Society: Bridging the Gap Between State Uniformity and Multicultural Identity Patterns, (Yale University - University of Atma Jaya Yogyakarta, Yogyakarta 2010).

Martinus Sardi, 2012: "Manusia Membuat Hukum bagi Dirinya Sendiri: Refleksi Filosofis Atas Hukum Yang Berperspektif Hak Asasi Manusia", dalam: Menafsir Ulang Strategi Kebudayaan 
Indonesia (Universitas Atma Jaya Yogyakarta - Penerbit

Kanisius, Yogyakarta, 2012), $71-92$.

Martinus Sardi, 2014: "Menuju Masyarakat Berwawasan HAM:

Berbasis Lokal, Bervisi Internasional", dalam: Muh. Latif Fauzi dan Sulhani Herwawan (ed.), Islam dan HAM: Diskursus dan Pengalaman Indonesia, Kuakaba Dipantara, Yogyakarta, 31 54.

Martinus Sardi, 2015: "Membangun Budaya Damai dalam Masyarakat ASEAN", dalam: Mujiyana dan Martino Sardi (ed.), Proceeding Seminar Nasional: Peluang dan Tantang-an Menghadapi Masyarakat Ekonomi ASEAN (MEA) - Perspektif Hukum dan Perlin-dungan Sumber Daya Laut, Laboratorium Ilmu Hukum, FH UMY, Yogyakarta, 451-457.

Martinus Sardi, 2016: "The Promotion and Protection of Human Rights for International Justice", in: Proceedings International Conference on Social Politics, Yogyakarta January 26 - 28, 2016, The Challenges of Social Sciences in a Changing World, Proceeding Books By Faculty of Social and Political Sciences Universitas Muhammadiyah Yogyakarta (UMY) For the International Conference on Social Politics Volume II, 861 867.

Muladi (ed.), 2005: Hak Asasi Manusia: Hakekat, Konsep dan Implementasinya dalam Perspektif Hukum dan Masyarakat, Refika Aditama, Bandung

Norbert Brieskorn, 1997: Menshenrechte: eine historischphilosophiische Grundlegung, Kohlhammer, Stutgart.

Raoy Gutman dan David Rieff (eds), 2009: Crimes of War, W.W. New York.

Satjipto Rahardjo, 2005: "HAM dalam Masyarakat", dalam: Muladi (ed.), Hak Asasi Manusia: Hakekat, Konsep dan Implementasinya dalam Perspektif Hukum dan Masyarakat, Refika Aditama, Bandung, 217 - 226.

Stefan Gosepath, 1998: "Sinn der Menshenrechte", dalam: Georg Lehmann dan Stefan Gosepath, Suhrkamp (ed.), Philosophie der Menshenrechte, Frankfurt am Mainz.

The Vienna Declaration: Vienna Declaration and Programme of Action, World Conference on Human Rights, Vienna, 14-25 June 1993,U.N. Doc. A/CONF.157/24 (Part I) at 20 (1993).

Undang-Undang Nomor 39 tahun 1999 tentang Hak-Hak Asasi Manusia.

US Department of the States, 2015: Indonesian 2014 Human Rights Report, Washington. 